\title{
Perinatal iron deficiency and neurocognitive development
}

\section{Emily C. Radlowski ${ }^{1,2}$ and Rodney W. Johnson ${ }^{1,2,3}$ *}

${ }^{1}$ Department of Animal Sciences, University of Illinois, Urbana, IL, USA

${ }^{2}$ Division of Nutritional Sciences, University of Illinois, Urbana, IL, USA

${ }^{3}$ Neuroscience Program, University of Illinois, Urbana, IL, USA

\section{Edited by:}

Michael Smith, Northumbria

University, UK

\section{Reviewed by:}

Anett Nyaradi, The University of

Western Australia, Australia

Leigh Riby, Northumbria University, UK

\section{*Correspondence:}

Rodney W. Johnson, Department of

Animal Sciences, University of Illinois, 4 Animal Sciences Lab, 1207 W

Gregory Drive, Urbana, IL, 61801, USA

e-mail:rwjohn@illinois.edu
Iron deficiency is the most common form of nutrient deficiency worldwide. It is highly prevalent due to the limited availability of high quality food in developing countries and poor dietary habits in industrialized countries. According to the World Health Organization, it affects nearly 2 billion people and up to $50 \%$ of women who are pregnant. Maternal anemia during pregnancy is especially burdensome to healthy neurodevelopment in the fetus because iron is needed for proper neurogenesis, development, and myelination. Maternal anemia also increases the risk of low birth weight, either due to premature birth or fetal growth restriction, which is associated with delayed neurocognitive development and even psychiatric illness. As rapid neurodevelopment continues after birth infants that received sufficient iron in utero, but that receive a low iron diet after 6 months of age, also show deficits in neurocognitive development, including impairments in learning and memory. Unfortunately, the neurocognitive complications of iron deficiency during critical pre- and postnatal periods of brain development are difficult to remedy, persisting into adulthood. Thus, preventing iron deficiency in the pre- and postnatal periods is critical as is devising new means to recapture cognitive function in individuals who experienced early iron deficiency. This review will discuss the prevalence of pre- and postnatal iron deficiency, the mechanism, and effects of iron deficiency on brain and cognitive development.

\section{Keywords: nutrition, iron deficiency, cognitive development, learning, memory, hippocampus}

\section{INTRODUCTION}

Iron deficiency is the primary cause of anemia, which affects roughly one-quarter of the world's population (McLean et al., 2009). As the most prevalent micronutrient deficiency in the world, iron deficiency affects all age groups, with the most common being children between the ages of 0 and 5 years (McLean et al., 2009). It was previously thought that neonates were protected from iron deficiency, in all but the most severe cases of maternal anemia, due to mobilization of iron stores accumulated in utero (Allen, 2000). However, it is now documented that even mild iron deficiency in the mother reduces iron stores in the fetus, resulting in a neonatal iron-deficient condition (Rao and Georgieff, 2002). Neonatal iron deficiency is also greater in infants born prematurely or of a diabetic mother (Lozoff et al., 2006). As the incidence of both these conditions is increasing worldwide (Beck et al., 2010; Martin et al., 2010; Danaei et al., 2011), it is likely that iron deficiency in infants will become an even greater concern in the future.

The impact of perinatal iron deficiency on human brain and cognitive development is of particular interest because the brain growth spurt that begins in the last one-third of pregnancy continues the first 2 years after birth due to dendritic growth, synaptogenesis, and glial cell proliferation (Courchesne et al., 2000; Gogtay et al., 2006). Neurogenesis in the hippocampal dentate gyrus also persists in the neonatal period (and throughout adulthood), and recent evidence indicates lingering neurogenesis in different cortical regions, including the prefrontal cortex in human infants (Sanai et al., 2011; Feliciano and Bordey, 2012). Total brain volume doubles the first year and reaches $80-90 \%$ of adult volume by age two (Knickmeyer et al., 2008). This phase of rapid growth represents a sensitive period, wherein environmental insults alter neurodevelopment (McEwen, 1999).

One such insult is iron deficiency. The hippocampus, a brain area important in learning, memory, and cognition, is highly susceptible to iron deficiency during the late fetal and early neonatal time period. For example, iron deficiency in the perinatal period is associated with altered expression of genes critical for hippocampal development and function (Carlson et al., 2007). Moreover, early iron deficiency causes neurocognitive dysfunction both during deficiency and after repletion (Beard and Connor, 2003; Jorgenson et al., 2005). Thus, preventing iron deficiency in the perinatal period is critical as is devising new means to recapture cognitive function in individuals who experienced early iron deficiency. Although iron deficiency is a major concern across the lifespan, this review will focus on the prevalence of pre- and postnatal iron deficiency, perinatal iron homeostasis, and the effects of perinatal iron deficiency on brain and cognitive development.

\section{PREVALENCE OF IRON DEFICIENCY AND IRON DEFICIENCY ANEMIA}

Of all micronutrient deficiencies, iron deficiency is most prevalent worldwide. It affects all age groups and demographics; however, 
prevalence is higher in pubescent women, pregnant women, infants and preschool-age children. Rates of anemia in nonpregnant women of childbearing age reach approximately $40 \%$ in developing countries and $20 \%$ in industrialized countries (McLean et al., 2009). The incidence of iron deficiency anemia increases further during pregnancy, with rates in developing and industrialized countries reaching 59\% and 24\%, respectively. The large increase in iron deficiency in pregnant women in developing countries may be due to poor nutrition education and lack of iron supplements (Pasricha et al., 2013).

Infants born full term with an appropriate weight for gestation have iron stores that are adequate for about 6 months. This is vital because the neonatal gut is developmentally immature and infants are unable to regulate iron absorption until 6-9 months of age (Domellöf et al., 2002). Furthermore, iron content of breast milk is very low (approximately 35-40 $\mu \mathrm{g} / \mathrm{dL}$ ). Although information on iron deficiency in infants less than 1 year of age is lacking, the Pediatric Nutrition Surveillance System (PedNSS) reported hemoglobin in a national sample of infants from families participating in the Special Supplemental Nutrition Program for Women, Infants, and Children (i.e., Supplemental Nutrition Assistance Program (SNAP; Polhamus et al., 2004)). In 2003, $16.2 \%$ of infants aged $6-11$ months, and $15 \%$ of children aged $12-$ 17 months qualified as having iron deficiency anemia (Polhamus et al., 2004). In a Brazilian community, iron deficiency anemia in infants (average age 11.6 months) reached nearly 26\% (Konstantyner et al., 2012); and in Canada, the rate of iron deficiency anemia in Cree Indian infants (average age 9 months) was nearly $32 \%$ (Willows et al., 2000). Sadly, in most countries including the U.S., the occurrence of iron deficiency worsens in preschool-aged children (CDC, 2011; see Table 1).

\section{MATERNAL IRON DEFICIENCY AND IRON DEFICIENCY ANEMIA: EFFECTS ON NEONATAL IRON STATUS}

As iron is concerned, the developing fetus was once considered a "perfect parasite," able to acquire sufficient iron from the mother even when she was iron deficient (Young et al., 2012). This notion has fallen by the wayside, however, and it is now clear that neonatal iron stores can be compromised when the mother is iron deficient or anemic. For example, under steadystate conditions serum ferritin concentration correlates with total body iron stores. New born infants from iron deficient mothers with low serum ferritin levels also had low serum ferritin indicating there is a limited capacity for the fetus to accumulate iron from low maternal stores (Jaime-Perez et al., 2005). Gestational iron deficiency also appears to have a programming effect on the physiologic mechanisms responsible for iron homeostasis resulting in offspring that are more likely to develop iron deficiency in the future regardless of adequate nutrition (De Pee et al., 2002; Georgieff et al., 2002; Emamghorashi and Heidari, 2004. Multiple studies have shown that iron status in infants born to iron deficient mothers is still abnormally low 9 months after birth despite being provided adequate dietary iron (Georgieff et al., 2002; Geltman et al., 2004).

The timing of iron deficiency during pregnancy is critical. First, there is an important need for iron early in pregnancy for neural development. In a recent study in rats, four dietaryfeeding regimens were used to render the developing fetuses iron deficient at different stages of gestation. Maternal iron restriction beginning prior to conception and during the first one-third of pregnancy was associated with embryonic iron deficiency, postnatal anemia, reduced iron levels in the central nervous system, and decreased neural conduction velocities in an auditory brainstem response test conducted at postnatal day 45 (Mihaila et al., 2011). Importantly, the functional neural impairments were not induced when maternal iron restriction was initiated at the beginning of the last one-third of pregnancy. It's also noteworthy that in this study, the mothers were not anemic; indicating poorly timed iron deficiency is sufficient to disrupt neural development and function. Second, as the fetal liver continues to grow, most (> $66 \%$ ) of the infants total body iron is acquired during the third trimester of pregnancy (Allen, 2000). Hence, infants born preterm and/or low birth weight have poorer iron stores and are a high risk population for iron deficiency (Scholl, 2011).

\section{IRON HOMEOSTASIS IN THE BRAIN OF INFANTS}

After 6 months of age, the blood-brain barrier is a major control point for the entry of iron into the brain, although the choroid plexus (the vasculature responsible for producing cerebrospinal fluid) is also a location of regulation for iron entry (Beard and Connor, 2003). The blood-brain barrier is important, as it prevents the brain from having direct access to the iron in the blood plasma, allowing for greater regulation (Piñero and Connor, 2000). Transferrin (Tf) receptors are present on the endothelial cells that make up the blood-brain barrier to allow for the binding and endocytosis of transferrin-bound iron into the brain (Beard, 2001). The rate of iron entry into the brain is increased during iron deficiency (Taylor et al., 1991), which is due to an increased amount of Tf receptors present on the cells of the blood-brain barrier (van Gelder et al., 1998), as well as a possible role for regulation by astrocytes (Beard and Connor, 2003).

Table 1 | Prevalence of iron deficiency anemia around the world.

\begin{tabular}{|c|c|c|c|}
\hline & & Iron deficiency anemia & Iron deficiency \\
\hline \multirow[t]{3}{*}{ Industrialized countries } & Pregnant women & $24 \% *$ & \multirow{6}{*}{$\begin{array}{l}\text { Iron deficiency is not commonly tested for } \\
\text { and rates around the world are unknown at } \\
\text { this time, but estimated to be much higher } \\
\text { than for iron deficiency anemia }\end{array}$} \\
\hline & Infant (0-12 months) & $16.2 \%{ }^{\dagger}$ & \\
\hline & Children (1-5 years) & $25 \% *$ & \\
\hline \multirow[t]{3}{*}{ Developing countries } & Pregnant women & $59 \% *$ & \\
\hline & Infant (0-12 months) & $40 \% \neq$ & \\
\hline & Children (1-5 years) & $67 \% *$ & \\
\hline
\end{tabular}

*McLean et al. (2009), † Polhamus et al. (2004), “ Chaparro (2008). 
In the newborn infant, the story is a bit different. At birth, the blood-brain barrier is incompletely developed: it prevents iron transport proteins from diffusing into the brain but it lacks the ability to transfer iron from the blood into the brain parenchyma (Collard, 2009). Studies done in rat pups showed that iron regulatory proteins, which are involved with the regulation of $\mathrm{Tf}$ receptor, were not readily expressed until post-natal day 15 , when peak myelination occurs in the rat (Siddappa et al., 2002). It is not known for human infants when the blood-brain barrier fully matures, but it has been estimated to occur by 6 months of age (Rice and Barone, 2000). During prenatal development iron accumulates in the brain so levels are highest immediately after birth (Siddappa et al., 2003). Due to poor bioavailability and low levels of iron in human breast milk, infant brain iron concentration decreases the first 6 months after birth, until the gastrointestinal tract and blood-brain barrier mature and are able to absorb dietary iron and regulate its entry into the brain, respectively. This coincides with the onset of myelination and an increase in transferring mRNA levels in brain (Connor et al., 1987; Connor and Menzies, 1996; Roncagliolo et al., 1998). Since oligodendrocytes synthesize Tf, the brain is the only organ in which Tf mRNA increases post-natally (Bloch et al., 1985). The developmental timeline for mechanisms responsible for iron homeostasis underscore the importance of maternal iron status during pregnancy.

Once iron penetrates the blood-brain barrier, much less is known about how it is distributed to different brain regions. Most likely $\mathrm{Tf}$ (secreted by the choroid plexus, which is another point of regulation) is the primary method for the distribution of iron in the brain (Beard, 2001); however, it is also possible for iron to be transported by binding to ferritin (Piñero and Connor, 2000). The iron can then be taken up by cells in various brain regions that express receptors for Tf and/or ferritin, with the expression of these receptors as the mechanism of regulation (Beard and Connor, 2003). This leads to an uneven distribution of iron between the various brain regions, which changes throughout the lifetime (Beard, 2001). In general, the globus pallidus, red nucleus, substantia nigra, and caudate putamen have higher iron concentrations throughout life, and the brain tends to accumulate iron with age (Piñero and Connor, 2000).

\section{NEUROCOGNITIVE DEFICITS RESULTING FROM PERINATAL IRON DEFICIENCY}

One of the first studies to look at the effect of iron deficiency on cognition in humans used the Bayley Scales of Infant Development, which assess motor, language, and cognitive development in infants and toddlers, and compared 9-26 month old infants who were given iron supplements to those given a placebo. Each group was tested and then re-tested within 8 days of the initial exam. The results showed an improved scores within the Mental Development Index for the iron supplemented group (Oski and Honig, 1978), which resulted in a surge of interest in this topic (Yehuda et al., 2010). Many different studies have looked at iron deficiency during various times of development; however, the most sensitive period (and the period that can cause the most irreversible damage) is the neonatal period, which is between 0 and 24 months of age (Pollitt, 1993). Although supplementation with iron has been shown to correct some of the cognitive deficits during this period, lower I.Q. and achievement test scores have still been found after treatment (Lozoff, 1989).

Many studies have investigated the impact of neonatal iron status at various times during this critical period and the effects that decreased iron levels have on cognition. In Papua New Guinea, infants who were given an iron dextran shot at 2 months of age had longer attention spans at 1 year of age when compared to control (Heywood et al., 1989). A study done in Costa Rica found that infants who had lower iron levels scored lower in the Bayley Scales of Infant Development tests in both cognitive and motor skill tests (Lozoff, 1989). In Guatemala, researchers found that an intramuscular injection of iron dextran improved Bayley Scales of Infant Development test scores in babies 6-24 months old after just one week, while oral supplementation did not show an effect within the week studied (Lozoff et al., 1982). In Chile, infants 3 months of age, were given either iron fortified formula or control diet for 12 months (Walter et al., 1983). At the conclusion of the diet intervention, Bayley Scales of Infant Development were administered. After the initial test, all infants received a trial of orally administered ferrous sulfate daily and then retested within 15 days (Walter et al., 1983). A similar relationship between low iron levels and lower Bayley Scales of Infant Development scores was found (Walter et al., 1983). Studies in Indonesia found that 8 weeks of oral supplementation of iron in anemic preschool aged children reduced deficits in visual attention and concept acquisition compared to children who were not given supplementation (Soewondo et al., 1989). Also in Indonesia, when 12-18 month old infants that were diagnosed with iron deficiency anemia were given an oral iron intervention, Bayley Scales of Infant Development scores significantly improved compared to those given a placebo, even after only 4 months of supplementation (Idjradinata and Pollitt, 1993). Nine and twelve month old infants were tested for their ability to discriminate a highly familiar stimulus, their mother's face, from a stranger's face using an electroencephalogram (Burden et al., 2007). At 9 months infants that were iron sufficient showed greater attentional response to the mother's face and greater updating of memory to the stranger's face, while iron deficient infants did not show this response until 12 months of age, suggesting a delay in cognitive development (Burden et al., 2007). It has also been demonstrated that infants with low serum ferritin concentrations have abnormal auditory recognition memory (Siddappa et al., 2004). The infants in this study did not discriminate a familiar stimulus (mother's voice) from a novel stimulus (stranger's voice) with the same vehemence as an iron sufficient infant (Siddappa et al., 2004). These findings suggest abnormalities in structures that mediate recognition and memory function, including the hippocampus (Georgieff, 2008).

Being iron deficient at birth seems to cause long term deficits as well. Five year old children, who were born either iron deficient, scored lower on tests of language ability, fine-motor skills, and tractability, when compared to children who were iron sufficient at birth (Tamura et al., 2002). In Israel, it was found that children who were born premature and had low ferritin levels at birth performed significantly worse on tests involving spatial cognition and processing of auditory signals when tested at 9 to 10 years of age, even though their hemoglobin levels had returned to normal (Armony-Sivan et al., 2004; Yehuda and Yehuda, 2006). Another 
study showed similar results in that Costa Rican teens that were severely iron deficient during infancy, despite resolution of anemia while an infant, showed deficits when given neurocognitive tests (Trail Making test, Intra-Extra-dimensional Shift, Stockings of Cambridge, Spatial Working Memory, Rapid Visual Information Processing, Pattern Recognition Memory, and Spatial Recognition Memory) at the age of 19 years old, when compared to teens that were iron sufficient during infancy (Lukowski et al., 2010).

Of course, studies in animals have greatly advanced the knowledge of iron deficiency and its effects on cognitive performance. The fact that the avoidance response is affected by iron deficiency was one of the first cognitive aspects studied in rodents. Rats placed on an iron deficient diet at an early age showed deficits in both passive avoidance, where the rat had to inhibit its activity (i.e., not leave a platform and enter a chamber) in order to avoid shock, and active avoidance (i.e., where rats had to move into another chamber of the testing area in order to avoid shock) (Weinberg et al., 1979, 1981). Fear conditioning (as measured by heart rate deceleration in a cage where the rat had been shocked previously, as well as exposure to a tone that was played during the shock in a novel cage) was also impaired in iron deficient rats (McEchron et al., 2005).

Iron deficient diets also resulted in cognitive deficits in the Morris Water Maze, a hippocampal-dependent task which requires the rat to develop a spatial map of the area surrounding the pool in order to reach a hidden platform (Yehuda and Youdim, 1989). Similar deficits were observed in a water Y-maze (where the rat had two choices and a dry platform was placed at the end of the arm of the correct choice as a reward), including increased incorrect arm entries and a longer time to reach the platform (Yehuda et al., 1986), both of which indicate cognitive deficits. A recent study with piglets also demonstrated the effects of early-life iron deficiency on hippocampal-dependent learning (Rytych et al., 2012). Neonatal piglets placed on liquid diets of varying iron content (adequate, mildly deficient, and a severely deficient) 2 days after birth underwent repeated cognitive testing beginning about 2 -weeks later using a T-maze task to measure spatial learning and memory. Severely iron deficient piglets were not able to successfully learn the task, while mildly deficient piglets took longer to learn compared to controls. In addition to poor performance, both sets of iron deficient piglets had less iron present in the hippocampus compared to controls (Rytych et al., 2012). These rodent and piglet studies confirmed that the magnitude of the cognitive effects observed correlated with the duration and severity of the iron deficiency.

The timing of iron deficiency during the perinatal period can also affect learning and memory. A pre-natal, post-natal, and pre+post-natal iron deficiency paradigm was used with mice pups to examine the effects of iron deficiency on learning and memory (Ranade et al., 2013). Mice pups that were pre-natal iron deficient or pre+ post-natal iron deficient performed poorly in a radial arm maze task; performance was better for pups in the post-natal deficient group, although their performance did not match that of pups provided adequate iron in both the pre- and postnatal periods. Even when pre-natal iron deficient pups became iron sufficient after birth, they still exhibited a poor ability to utilize refer- ence memory, suggesting the hippocampus is highly vulnerable to iron deficiency in the pre-natal period (Ranade et al., 2013). However, the fact that performance of the post-natal iron deficient group was intermediate to the other iron deficient groups and control confirms that the window of vulnerability to iron deficiency for the hippocampus does not close immediately at birth.

Iron deficiency decreases brain iron concentration, which leads to numerous behavioral symptoms, such as irritability, apathy, reduced ability to concentrate, and other cognitive deficits (Piñero and Connor, 2000) (Table 2). Other important behavioral problems have been reported in association with iron deficiency as well. For example, children with Attention Deficit Hyperactivity Disorder (ADHD) were found to have lower levels of serum ferritin, an indication of reduced iron storage (Konofal et al., 2004). Iron-deficient animals develop ADHD-like behavior that has been linked to the dopaminergic system (Lahat et al., 2011). Deficits in motor development are also a symptom of iron deficiency in the neonate. In addition to cognitive development, the Bayley Scales of Infant Development also assesses fine and gross motor skills. Numerous studies (Lozoff et al., 1982; Walter et al., 1983; Lozoff, 1989; Idjradinata and Pollitt, 1993) indicate iron deficiency is associated with poorer scores in the motor function assessment within of the Bayley Scales of Infant Development. Further, anemic infants had low Mental and Psychomotor Development Index scores, even after 3 months of iron therapy. The anemic infants also showed deficits in language capability and coordination (Walter et al., 1989). In rodents, iron deficiency is associated with delayed development of surface righting, bar hold, forelimb placing, and negative geotaxis (Beard et al., 2006).

\section{IRON UTILIZATION WITHIN THE BRAIN}

So what are some potential mechanisms underlying iron deficiency-related deficits in cognition? Iron is important for erythropoiesis, formation of hemoglobin and myoglobin, gene transcription, cellular enzyme reactions, and important oxidation-reduction actions (Lieu et al., 2001). All of these, of course, are important for proper brain function, so it is not surprising that iron deficiency results in behavioral disorders and deficits in learning and memory (Rao and Georgieff, 2007). In humans, the hippocampus matures most rapidly over a short period of time: from late gestation to 2-3 years of age. During this period, there is an increase in iron uptake and utilization as well as neurogenesis, dendrite growth, myelination, synaptogenesis, and neurotransmitter synthesis (Fretham et al., 2011). Hippocampal-dependent memory appears and matures between 3-18 months of age (Nelson, 1995). Because infants are unable to fully regulate iron transport across the blood-brain barrier the first 6 months after birth, it is paramount that infants have adequate iron stores at birth.

Although hippocampal neurogenesis continues into adulthood, it occurs at a much greater rate prenatally and in the early postnatal period (Figure 1). The newborn neurons integrate into the developing neural circuitry and are thought to be important for learning and memory. Thus, in critical developmental periods environmental insults that inhibit neurogenesis or alter neuron maturation will likely affect present and future behavior. Iron deficiency has been shown to inhibit 


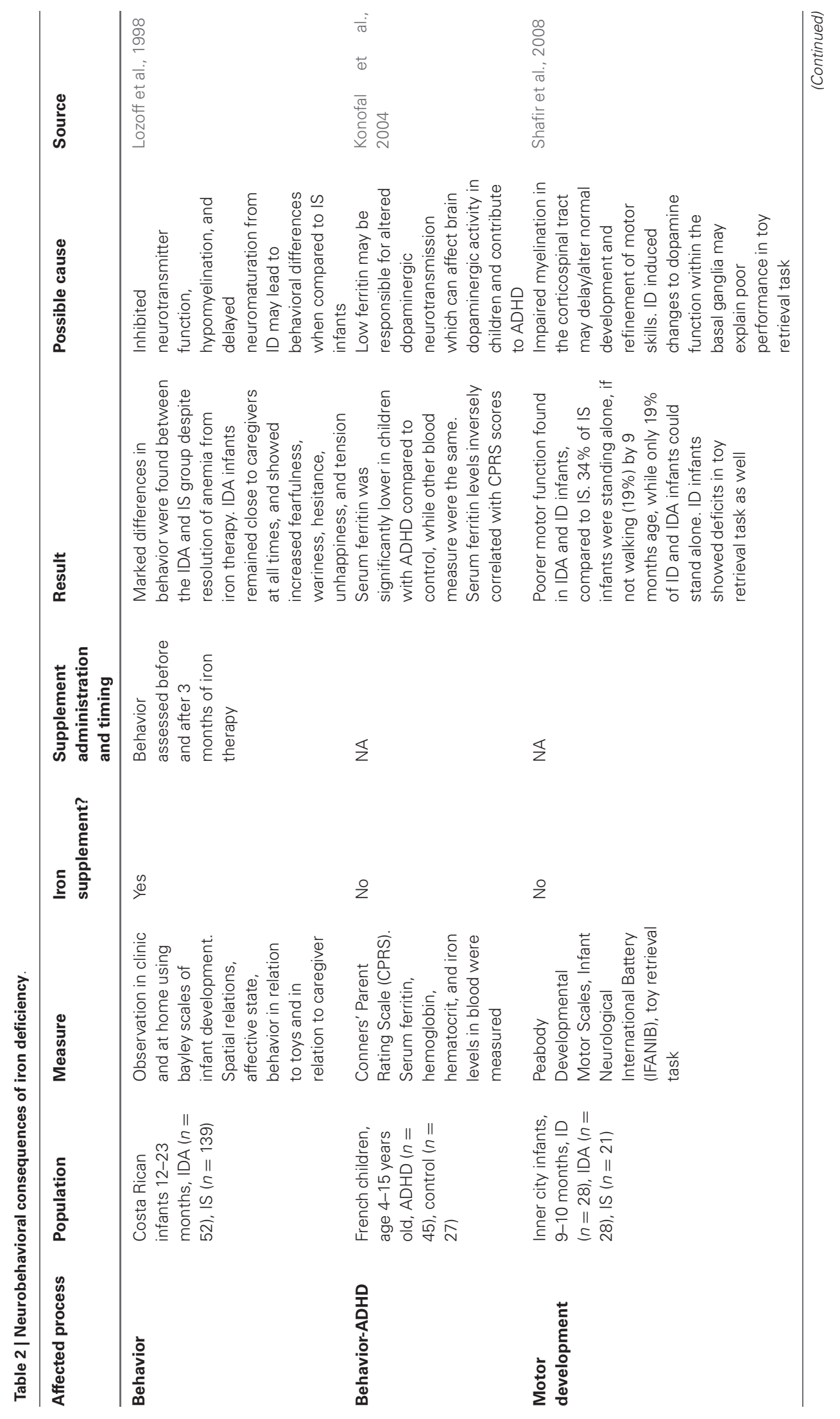




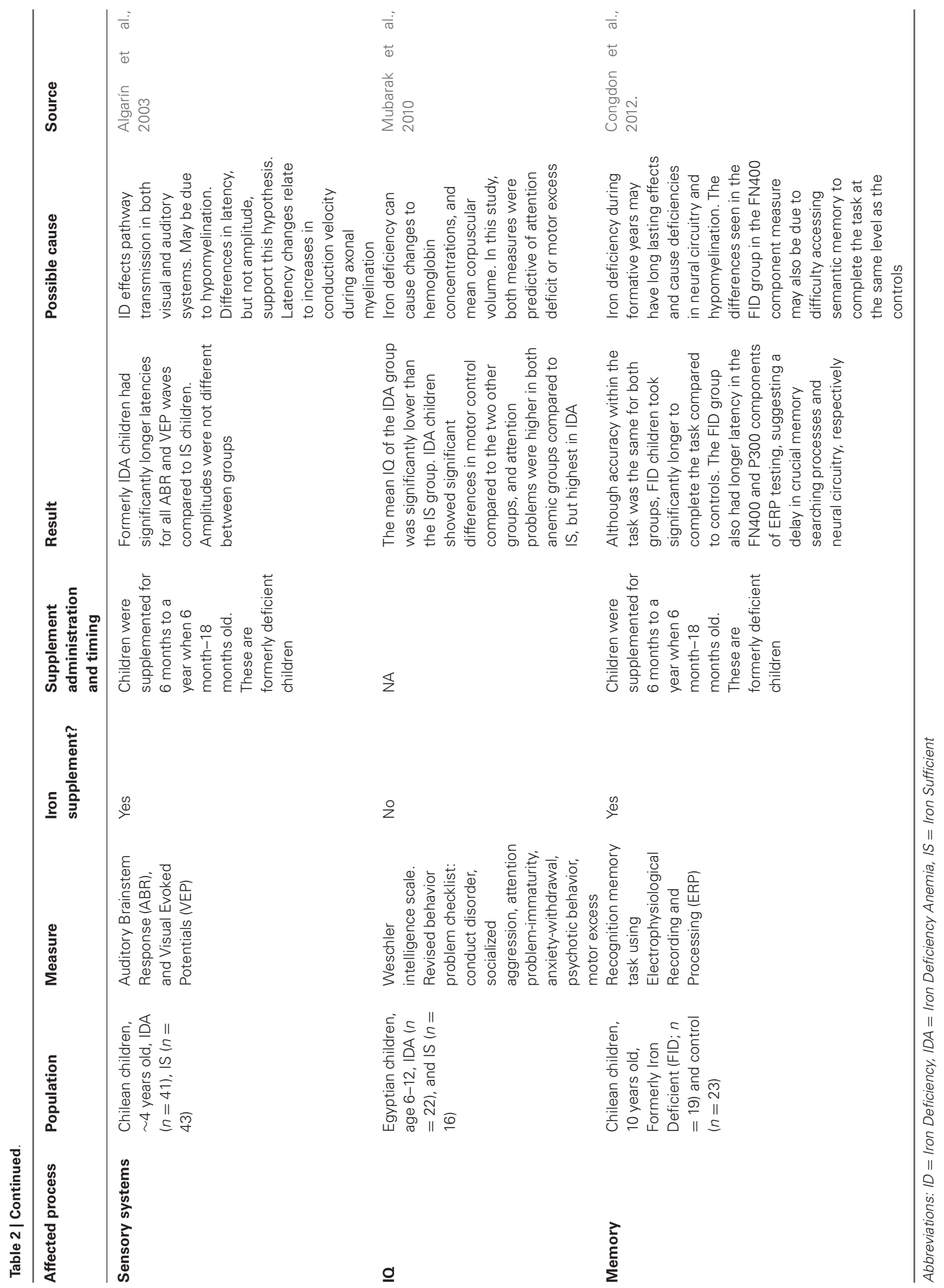




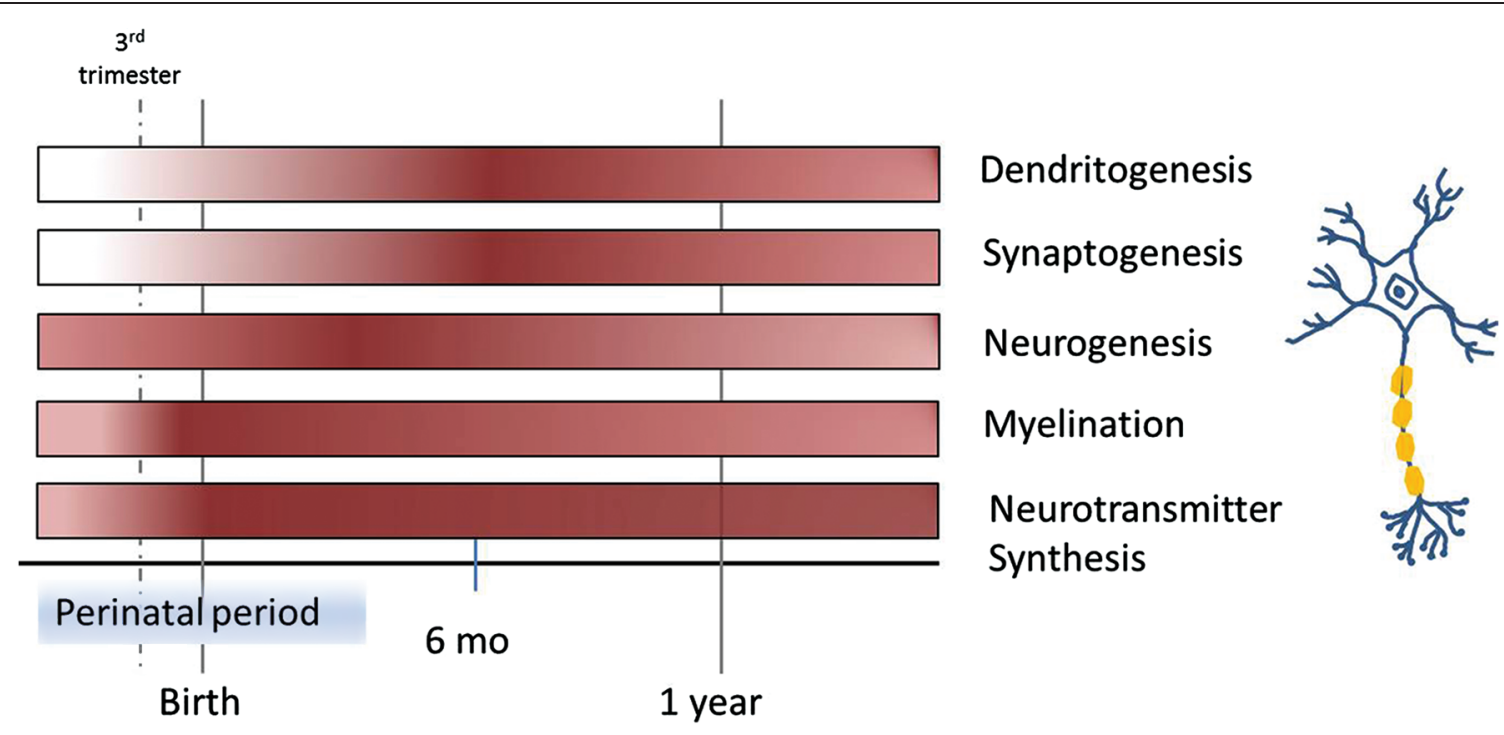

FIGURE 1 | Time course of different processes in brain development involved in learning and memory over the first year of life, highlighting periods of vulnerability to iron deficiency. Color intensity corresponds with the start, as well as peaks within each process.

neurogenesis in the developing hippocampus. Young rats whose mothers were fed an iron-deficient diet and who were born with iron deficiency, showed decreased brain-derived neurotrophic factor (BDNF) levels, down-regulation of BDNF target genes, and altered neuronal differentiation (Tran et al., 2008). Another study was carried out to investigate the effects of perinatal iron deficiency on hippocampal development in mice (Ranade et al., 2013). Iron deficiency in the pre- or postnatal period reduced BDNF and neurogenesis in the hippocampal dentate gyrus of pups. The impact of iron deficiency persisted, as the numbers of hippocampal pyramidal and granule cells were reduced in adults. Moreover, the structural and molecular defects in the pups were correlated with performance in hippocampal-dependent behavioral tasks, with pups from dams that were iron deficient throughout pregnancy and lactation displaying a broad array of defects, while pups from dams that were iron deficient only during pregnancy or during lactation displaying subsets of defects. These findings suggest that iron homeostasis is critical for the expression of neurotrophic factors that support brain development and provide a molecular basis for behavioral deficits related to perinatal iron deficiency (Lozoff et al., 2006).

Iron deficiency can cause changes to neuronal morphology. Neuronal shape is directly related to the computations performed by the cell and is crucial to information processing. Two key morphological features of neurons are dendritic arbor structure and spine density and geometry (Spruston, 2008). The developing arbor requires external inputs to stimulate and support branching morphogenesis. The arbor relies on external cues BDNF that signal via their respective transmembrane proteins. These in turn modulate factors that facilitate elongation and branching by promoting or reducing actin polymerization (Ackermann and Matus, 2003; Sekino et al., 2007). This process is not restricted to early developmental periods because it is also necessary for reshaping neural circuitry during experience-dependent learning throughout life (i.e., synaptic plasticity; Figure 1; Bagot et al., 2009). Like dendritic arbor structure, a spine's morphology can impact its function (Spruston, 2008). At post-natal day 15, CA1 pyramidal neurons in rats that underwent a period of iron deficiency in utero showed reduced dendritic branching and smaller spine head diameters (Brunette et al., 2010). Smaller spine heads could reduce conduction velocity resulting in less coordinated input to the soma as well as represent smaller post-synaptic density which could also affect signal transmission (Hodgkin, 1954).

Consistent with the structural changes noted above, iron deficiency also impacts synaptic plasticity in the developing hippocampus of rats (Jorgenson et al., 2005). For example, prenatal iron deficiency disrupted synaptic plasticity in the developing CA1 region of the hippocampus, but these differences were also apparent in adulthood, after iron repletion. When iron was replete, rat pups demonstrated no developmental increase in synaptic strength, as seen in control animals. It is hypothesized that major developmental events related to proper dendrite outgrowth and synaptogenesis were thwarted due to the unavailability of adequate iron (Jorgenson et al., 2005). This certainly may contribute to the lasting effects of iron deficiency on hippocampal structure and function.

In addition to marked changes in dendrite out growth and synaptogenesis, hypomyelination occurs when iron availability is limited. Proper myelination is important for rapid impulse transmission along axons. Myelination begins in the third trimester of the fetal period and progresses rapidly through infancy (Figure 1; Nakagawa et al., 1998). In the central nervous system, oligodendrocytes are responsible for myelination of axons. As mentioned before, oligodendrocytes synthesize Tf to mobilize needed iron, assuming it is readily available. Studies in humans and rats have demonstrated that iron deficiency can severely affect myelination. Increased latency of auditory brain stem potentials and visual evoked potentials (indirect markers of myelination) has been reported in iron deficient children (Roncagliolo et al., 1998; Algarín et al., 2003). Oligodendrocytes synthesize fatty acids and 
cholesterol for myelin (Mackler et al., 1979; McKay et al., 1983). In a rat model, restriction of dietary iron during gestation and the early post-natal period resulted in significantly less myelin proteins, lipids, and cholesterol in the spinal cord, brain stem, and cerebellar white matter (Yu et al., 1986; Ortiz et al., 2004). Additionally, rats that were iron deficient in the perinatal period displayed deficits in myelinogenesis at adulthood, even though iron stores were replete (Ortiz et al., 2004). Finally, placing rats on an iron-deficient diet post-weaning lead to a significant decrease in myelination indices in the hindbrain and cerebrum (Beard and Connor, 2003). This suggests that the need and usage of iron by oligodendrocytes does not end during the perinatal period and that the adult brain still requires adequate iron.

Iron is also essential for a number of enzymes involved in neurotransmitter synthesis, including tryptophan hydroxylase used to produce serotonin, and tyrosine hydroxylase used to synthesize norepinephrine and dopamine. Neurotransmitter synthesis begins during embryogenesis (Figure 1; Herlenius and Lagercrantz, 2001). Dopamine is important for regulating cognition and emotion, reward and pleasure, movement, and hormone release (Dunnett et al., 2005). Striatal networks, with dopamine as the major neurotransmitter, relate to higher order cognitive and emotional processes, motivated behavior, positive affect, and reward-related processing, as well as motor function (Dunnett et al., 2005). Studies in humans have shown that young adults, who were iron deficient while an infant, tended to perform more poorly on tasks that involved inhibitory control, set-shifting, and planning, all of which are classified as executive functions that utilize striatal networks that rely on dopamine (Lukowski et al., 2010). Studies in rodents have determined that dopaminergic neurons co-localize with iron throughout the brain, that extracellular dopamine and norepinephrine are elevated in brains of iron-deficient rats, and that the density of dopamine receptors are altered in iron deficiency. These alterations are tightly connected to the extent of iron loss in each brain region (Beard and Connor, 2003). Other studies demonstrate that serotonin transporter (SERT) and norepinephrine transporter densities are also altered by iron deficiency (Burhans et al., 2005). Serotonin is particularly important for proper wiring of neural circuits and is highly implicated in neurodevelopmental disorders, such as

\section{REFERENCES}

Ackermann, M., and Matus, A. (2003). Activity-induced targeting of profilin and stabilization of dendritic spine morphology. Nat. Neurosci. 6, 1194-1200. doi: 10.1038/ nn 1135

Ahmed, T., Hossain, M., and Sanin, K. I. (2012). Global burden of maternal and child undernutrition and micronutrient deficiencies. Ann. Nutr. Metab. 61(Suppl. 1), 8-17. doi: 10.1159/000345165

Algarín, C., Peirano, P., Garrido, M., Pizarro, F., and Lozoff, B. (2003). Iron deficiency anemia in infancy: long-lasting effects on auditory and visual system functioning. Pediatr.

autism, anxiety, or depression (Calabrese et al., 2013). The SERT, which is responsible for re-uptake of serotonin within the brain, is the predominant mechanism controlling strength and duration of serotonergic neurotransmission (Gaspar et al., 2003). SERT is expressed more during development than in adulthood (Daws and Gould, 2011). Iron deficiency leads to decreased expression of SERT which in turn exacerbates the decreased expression of BDNF. As previously noted, a reduction in BDNF can have serious consequences for hippocampal structure and function leading to deficits in learning and memory.

\section{CONCLUSION}

Iron deficiency is the leading micronutrient deficiency in the world. It affects people of all ages, but is most detrimental to infants and children. In developing countries, approximately $12 \%$ of children under 5 will die from a micronutrient deficiency (Ahmed et al., 2012). Children who survive will likely be iron deficient, if not anemic. In industrialized countries like the United States, the incidence of iron deficiency is increasing, probably due in part to the increase in the number of children and adults who are overweight or obese (inflammation disrupts iron homeostasis) (Del Giudice et al., 2009). As iron deficiency inhibits learning as well as motor and emotional development, individuals exposed to perinatal iron deficiency are at high risk for failing to reach educational milestones later in life. Moreover, as adults they are more likely to bear children who also experience iron deficiency. Hence, iron deficiency in one generation can beget iron deficiency in the next generation, and so on. Given the consequences of developmental delays in neurocognitive function, such as decreased motor development, lower IQ, difficulties with learning and memory (refer to Table 2 for more evidence), strategies to prevent perinatal iron deficiencies and to promote neural plasticity in individuals exposed to poor iron status during key developmental periods, warrants more attention.

\section{ACKNOWLEDGMENTS}

Supported in part by HD069899 and AG16710. The authors would also like to thank Jennifer Rytych for her input and help with the content of this article.

gyrus. Neurobiol. Learn. Mem. 92, 292-300. doi: 10.1016/j.nlm.2009. 03.004

Beard, J. L. (2001). Iron biology in immune function, muscle metabolism and neuronal functioning. J. Nutr. 131, 568S-580S.

Beard, J. L., and Connor, J. R. (2003). Iron status and neural functioning. Ann. Rev. Nutr. 23, 41-58. doi: 10. 1146/annurev.nutr.23.020102. 075739

Beard, J. L., Felt, B., Schallert, T., Burhans, M., Connor, J. R., and Georgieff, M. K. (2006). Moderate iron deficiency in infancy: biology and behavior in young rats. Behav. Brain Res. 170, 224-
232. doi: 10.1016/j.bbr.2006 02.024

Beck, S., Wojdyla, D., Say, L., Betran, A. P., Merialdi, M., Requejo, J. H., et al. (2010). The worldwide incidence of preterm birth: a systematic review of maternal mortality and morbidity. Bull. World Health Organ. 88, 31-38. doi: 10.2471/BLT.08.062554

Bloch, B., Popovici, T., Levin, M. J., Tuil, D., and Kahn, A. (1985) Transferrin gene expression visualized in oligodendrocytes of the rat brain by using in situ hybridization and immunohistochemistry. Proc. Natl. Acad. Sci. U S A 82, 6706-6710. doi: 10.1073/pnas.82. 19.6706 
Brunette, K. E., Tran, P. V., Wobken, J. D., Carlson, E. S., and Georgieff, M. K. (2010). Gestational and neonatal iron deficiency alters apical dendrite structure of cal pyramidal neurons in adult rat hippocampus. Dev. Neurosci. 32, 238-248. doi: 10. 1159/000314341

Burden, M. J., Westerlund, A. J., Armony-Sivan, R., Nelson, C. A., Jacobson, S. W., Lozoff, B., et al. (2007). An event-related potential study of attention and recognition memory in infants with irondeficiency anemia. Pediatrics 120, e336-e345. doi: 10.1542/peds.20062525

Burhans, M. S., Dailey, C., Beard, Z., Wiesinger, J., Murray-Kolb, L., Jones, B. C., et al. (2005). Iron deficiency: differential effects on monoamine transporters. Nutr. Neurosci. 8, 31-38. doi: 10. 1080/10284150500047070

Calabrese, F., Guidotti, G., Middelman, A., Racagni, G., Homberg, J., and Riva, M. (2013). Lack of serotonin transporter alters bdnf expression in the rat brain during early postnatal development. Mol. Neurobiol. 48, 244-256. doi: 10.1007/s12035-013$8449-\mathrm{z}$

Carlson, E. S., Stead, J. D., Neal, C. R., Petryk, A., and Georgieff, M. K. (2007). Perinatal iron deficiency results in altered developmental expression of genes mediating energy metabolism and neuronal morphogenesis in hippocampus. Hippocampus 17, 679-691. doi: 10. 1002/hipo.20307

CDC (US). Pediatric data tables: table 12D: 2011 Pediatric Nutrition Surveillance Summary: summary of trends in growth and anemia indicators children aged $<5$ years [cited June 19, 2012]. Available from: URL: http://www.cdc.gov/pednss/pednss_ tables/pdf/national_table12.pdf

Collard, K. J. (2009). Iron homeostasis in the neonate. Pediatrics 123, 12081216. doi: 10.1542/peds.2008-1047

Congdon, E. L., Westerlund, A., Algarin, C. R., Peirano, P. D., Gregas, M., Lozoff, B., et al. (2012). Iron deficiency in infancy is associated with altered neural correlates of recognition memory at 10 years. $J$. Pediatr. 160, 1027-1033. doi: 10. 1016/j.jpeds.2011.12.011

Connor, J. R., and Menzies, S. L. (1996). Relationship of iron to oligondendrocytes and myelination. Glia 17, 83-93. doi: 10.1002/(sici)10981136(199606) 17:2<83::aid-glial $>3$. $0 . \operatorname{co} ; 2-7$

Connor, J. R., Phillips, T. M., Lakshman, M., Barron, K. D., Fine, R. E., and Csiza, C. K. (1987). Regional variation in the levels of transferrin in the cns of normal and myelin-deficient rats. J. Neurochem. 49, 1523-1529. doi: 10.1111/j.14714159.1987.tb01023.x

Courchesne, E., Chisum, H. J., Townsend, J., Cowles, A., Covington, J., Egaas, B., et al. (2000). Normal brain development and aging: quantitative analysis at in vivo $\mathrm{mr}$ imaging in healthy volunteers1. Radiology 216, 672-682.

Chaparro, C. M. (2008). Setting the stage for child health and development: prevention of iron deficiency in early infancy. J. Nutr. 138, 25292533.

Danaei, G., Finucane, M. M., Lin, J. K., Singh, G. M., Paciorek, C. J., Cowan, M. J., et al. (2011). National, regional, and global trends in systolic blood pressure since 1980: systematic analysis of health examination surveys and epidemiological studies with 786 country-years and 5.4 million participants. Lancet 377, 568-577. doi: 10.1016/S01406736(10)62036-3

Daws, L. C., and Gould, G. G. (2011). Ontogeny and regulation of the serotonin transporter: providing insights into human disorders. Pharmacol. Ther. 131, 61-79. doi: $10.1016 /$ j.pharmthera.2011.03. 013

Del Giudice, E. M., Santoro, N., Amato, A., Brienza, C., Calabrò, P., Wiegerinck, E. T., et al. (2009). Hepcidin in obese children as a potential mediator of the association between obesity and iron deficiency. J. Clin. Endocrinol. Metab. 94, 5102-5107. doi: 10.1210/jc.2009-1361

De Pee, S., Bloem, M. W., Sari, M., Kiess, L., Yip, R., and Kosen, S. (2002). The high prevalence of low hemoglobin concentration among indonesian infants aged 3-5 months is related to maternal anemia. $J$. Nutr. 132, 2215-2221.

Domellöf, M., Lönnerdal, B., Abrams, S. A., and Hernell, O. (2002). Iron absorption in breast-fed infants: effects of age, iron status, iron supplements, and complementary foods. Am. J. Clin. Nutr. 76, 198-204.

Dunnett, S., Meldrum, A., and Muir, J. (2005). Frontal-striatal disconnection disrupts cognitive performance of the frontal-type in the rat. Neuroscience 135, 1055-1065. doi: 10.1016/j.neuroscience.2005. 07.033

Emamghorashi, F., and Heidari, T. (2004). Iron status of babies born to iron-deficient anaemic mothers in an iranian hospital. East. Mediterr. Health J. 10, 808-814.

Feliciano, D. M., and Bordey, A. (2012). Newborn cortical neurons: only for neonates? Trends Neurosci. 36, 5161. doi: 10.1016/j.tins.2012.09.004

Fretham, S. J., Carlson, E. S., and Georgieff, M. K. (2011). The role of iron in learning and memory. $A d v$. Nutr. 2, 112-121. doi: 10.3945/an. 110.000190

Gaspar, P., Cases, O., and Maroteaux, L. (2003). The developmental role of serotonin: news from mouse molecular genetics. Nat. Rev. Neurosci. 4, 1002-1012. doi: 10.1038/nrn1256

Geltman, P. L., Meyers, A. F., Mehta, S. D., Brugnara, C., Villon, I., Wu, Y. A., et al. (2004). Daily multivitamins with iron to prevent anemia in high-risk infants: a randomized clinical trial. Pediatrics 114, 86-93. doi: $10.1542 /$ peds.114.1.86

Georgieff, M. K. (2008). The role of iron in neurodevelopment: fetal iron deficiency and the developing hippocampus. Biochem. Soc. Trans. 36, 1267-1271. doi: 10. 1042/bst0361267

Georgieff, M. K., Wewerka, S. W., Nelson, C. A., and Deregnier, R.-A. (2002). Iron status at 9 months of infants with low iron stores at birth. J. Pediatr. 141, 405-409. doi: 10. 1067/mpd.2002.127090

Gogtay, N., Nugent, T. F., Herman, D. H., Ordonez, A., Greenstein, D., Hayashi, K. M., et al. (2006). Dynamic mapping of normal human hippocampal development. Hippocampus 16, 664-672. doi: 10. 1002/hipo.20193

Herlenius, E., and Lagercrantz, $\mathrm{H}$. (2001). Neurotransmitters and neuromodulators during early human development. Early Hum. Dev. 65, 21-37. doi: 10.1016/s03783782(01)00189-x

Heywood, A., Oppenheimer, S., Heywood, P., and Jolley, D. (1989). Behavioral effects of iron supplementation in infants in madang, papua new guinea. Am. J. Clin. Nutr. 50, 630-640.

Hodgkin, A. (1954). A note on conduction velocity. J. Physiol. 125, 221-224.

Idjradinata, P., and Pollitt, E. (1993). Reversal of developmental delays in iron-deficient anaemic infants treated with iron. Lancet 341, 1-4. doi: 10.1016/0140-6736(93) 92477-b

Jaime-Perez, J. C., Herrera-Garza, J. L., and Gomez-Almaguer, D. (2005). Sub-optimal fetal iron acquisition under a maternal environment.
Arch. Med. Res. 36, 598-602. doi: 10. 1016/j.arcmed.2005.03.023

Jorgenson, L. A., Sun, M., O'connor, M., and Georgieff, M. K. (2005). Fetal iron deficiency disrupts the maturation of synaptic function and efficacy in area cal of the developing rat hippocampus. Hippocampus 15 , 1094-1102. doi: 10.1002/hipo. 20128

Knickmeyer, R. C., Gouttard, S., Kang, C., Evans, D., Wilber, K., Smith, J. K., et al. (2008). A structural mri study of human brain development from birth to 2 years. $J$. Neurosci. 28, 12176-12182. doi: 10. 1523/JNEUROSCI.3479-08.2008

Konofal, E., Lecendreux, M., Arnulf, I., and Mouren, M.-C. (2004). Iron deficiency in children with attention-deficit/hyperactivity disorder. Arch. Pediatr. Adolesc. Med. 158, 1113-1115. doi: 10. 1001/archpedi.158.12.1113

Konstantyner, T., Roma Oliveira, T. C., and De Aguiar Carrazedo Taddei, J. A. (2012). Risk factors for anemia among brazilian infants from the 2006 national demographic health survey. Anemia 2012, 1-7. doi: 10. 1155/2012/850681

Lahat, E., Heyman, E., Livne, A., Goldman, M., Berkovitch, M., and Zachor, D. (2011). Iron deficiency in children with attention deficit hyperactivity disorder. Isr. Med. Assoc. J. 13, 530-533.

Lieu, P. T., Heiskala, M., Peterson, P. A., and Yang, Y. (2001). The roles of iron in health and disease. Mol. Aspects Med. 22, 1-87. doi: 10. 1016/s0098-2997(00)00006-6

Lozoff, B. (1989). Nutrition and behavior. Am. Psychol. 44, 231-236.

Lozoff, B., Beard, J., Connor, J., Felt, B., Georgieff, M., and Schallert, T. (2006). Long-lasting neural and behavioral effects of iron deficiency in infancy. Nutr. Rev. 64, S34-S43. doi: 10.1301/nr.2006.may.s34-s43

Lozoff, B., Brittenham, G. M., Viteri, F. E., Wolf, A. W., and Urrutia, J. J. (1982). The effects of short-term oral iron therapy on developmental deficits in iron-deficient anemic infants. J. Pediatr. 100, 351357. doi: 10.1016/s0022-3476(82) 80428-9

Lozoff, B., Klein, N. K., Nelson, E. C., Mcclish, D. K., Manuel, M., and Chacon, M. E. (1998). Behavior of infants with iron-deficiency anemia. Child Dev. 69, 24-36. doi: 10.1111/j. 1467-8624.1998.tb06130.x

Lukowski, A. F., Koss, M., Burden, M. J., Jonides, J., Nelson, C. A., Kaciroti, N., et al. (2010). Iron deficiency in infancy and neurocognitive 
functioning at 19 years: evidence of long-term deficits in executive function and recognition memory. Nutr. Neurosci. 13, 54-70. doi: 10. 1179/147683010X12611460763689

Mackler, B., Person, R., Miller, L. R., and Finch, C. (1979). Iron deficiency in the rat: effects on phenylalanine metabolism. Pediatr. Res. 13, 1010-1011. doi: 10.1203/00006450-19790900000012

Martin, J. A., Hamilton, B. E., Sutton, P. D., Ventura, S. J., Mathews, T., Kirmeyer, S., et al. (2010). Births: final data for 2007. Natl. Vital Stat. Rep. 58, 1-85.

McEchron, M. D., Cheng, A. Y., Liu, H., Connor, J. R., and Gilmartin, M. R. (2005). Perinatal nutritional iron deficiency permanently impairs hippocampus-dependent trace fear conditioning in rats. Nutr. Neurosci. 8, 195-206. doi: 10. 1080/10284150500162952

McEwen, B. S. (1999). Stress and hippocampal plasticity. Annu. Rev. Neurosci. 22, 105-122. doi: 10. 1146/annurev.neuro.22.1.105

McLean, E., Cogswell, M., Egli, I., Wojdyla, D., and De Benoist, B. (2009). Worldwide prevalence of anaemia, who vitamin and mineral nutrition information system, 1993-2005. Public Health Nutr. 12, 444-454. doi: 10. 1017/s1368980008002401

McKay, R. H., Higuchi, D. A., Winder, W. W., Fell, R. D., and Brown, E. B. (1983). Tissue effects of iron deficiency in the rat. Biochim. Biophys. Acta 757, 352-358. doi: 10. 1016/0304-4165(83)90061-2

Mihaila, C., Schramm, J., Strathmann, F. G., Lee, D. L., Gelein, R. M., Luebke, A. E., et al. (2011). Identifying a window of vulnerability during fetal development in a maternal iron restriction model. PLoS One 6:e17483. doi: 10.1371/journal. pone. 0017483

Mubarak, A., Fadel, W., Said, S., and Hammar, M. A. (2010). Profile of behavior and iq in anemic children. CNS Spectr. doi: 10. 1017/s1092852912000089. [Epub ahead of print].

Nakagawa, H., Iwasaki, S., Kichikawa, K., Fukusumi, A., Taoka, T., Ohishi, H., et al. (1998). Normal myelination of anatomic nerve fiber bundles: mr analysis. AJNR Am. J. Neuroradiol. 19, 1129-1136.

Nelson, C. A. (1995). The ontogeny of human memory: a cognitive neuroscience perspective. Dev. Psychol. 31, 723-738. doi: 10.1037/0012-1649. 31.5 .723
Ortiz, E., Pasquini, J., Thompson, K., Felt, B., Butkus, G., Beard, J., et al. (2004). Effect of manipulation of iron storage, transport, or availability on myelin composition and brain iron content in three different animal models. J. Neurosci. Res. 77, 681-689. doi: 10.1002/jnr.20207

Oski, F. A., and Honig, A. S. (1978). The effects of therapy on the developmental scores of iron-deficient infants. J. Pediatr. 92, 21-25. doi: 10. 1016/s0022-3476(78)80063-8

Pasricha, S.-R., Drakesmith, H., Black, J., Hipgrave, D., and Biggs, B.-A. (2013). Control of iron deficiency anemia in low- and middle-income countries. Blood 121, 2607-2617. doi: 10.1182/blood-2012-09-453522

Piñero, D. J., and Connor, J. R. (2000). Iron in the brain: an important contributor in normal and diseased states. Neuroscientist 6, 435-453. doi: 10.1177/107385840000600607

Polhamus, B., Dalenius, K., Thompson, D., Scanlon, K., Borland, E., Smith, B., et al. (2004). Pediatric Nutrition Surveillance: 2003 Report. US Department of Health and Human Services, Centers for Disease Control and Prevention.

Pollitt, E. (1993). Iron deficiency and cognitive function. Ann. Rev. Nutr. 13, 521-537. doi: 10.1146/annurev. nutr.13.1.521

Ranade, S. C., Nawaz, S., Chakrabarti, A., Gressens, P., and Mani, S. (2013). Spatial memory deficits in maternal iron deficiency paradigms are associated with altered glucocorticoid levels. Horm. Behav. 64, 26-36. doi: 10.1016/j.yhbeh.2013.04.005

Rao, R., and Georgieff, M. (2002). Perinatal aspects of iron metabolism. Acta Paediatr. Suppl. 91, 124-129. doi: $\quad 10.1111 /$ j.1651-2227.2002. tb02917.x

Rao, R., and Georgieff, M. K. (2007). Iron in fetal and neonatal nutrition. Semin. Fetal Neonatal Med. 12, 5463. doi: 10.1016/j.siny.2006.10.007

Rice, D., and Barone, S., Jr. (2000). Critical periods of vulnerability for the developing nervous system: evidence from humans and animal models. Environ. Health Perspect. 108, 511-533. doi: 10.2307/3454543

Roncagliolo, M., Garrido, M., Walter, T., Peirano, P., and Lozoff, B. (1998). Evidence of altered central nervous system development in infants with iron deficiency anemia at $6 \mathrm{mo}$ delayed maturation of auditory brainstem responses. Am. J. Clin. Nutr. 68, 683-690.

Rytych, J. L., Elmore, M. R., Burton, M. D., Conrad, M. S., Donovan, S. M., Dilger, R. N., et al. (2012).
Early life iron deficiency impairs spatial cognition in neonatal piglets. J. Nutr. 142, 2050-2056. doi: 10. 3945/jn.112.165522

Sanai, N., Nguyen, T., Ihrie, R. A., Mirzadeh, Z., Tsai, H.-H., Wong, M., et al. (2011). Corridors of migrating neurons in the human brain and their decline during infancy. Nature 478, 382-386. doi: 10.1038/nature10487

Scholl, T. O. (2011). Maternal iron status: relation to fetal growth, length of gestation, and iron endowment of the neonate. Nutr. Rev. 69 , S23-S29. doi: 10.1111/j.1753-4887. 2011.00429.x

Sekino, Y., Kojima, N., and Shirao, T. (2007). Role of actin cytoskeleton in dendritic spine morphogenesis. Neurochem. Int. 51, 92-104. doi: 10. 1016/j.neuint.2007.04.029

Shafir, T., Angulo-Barroso, R., Jing, Y., Angelilli, M. L., Jacobson, S. W., and Lozoff, B. (2008). Iron deficiency and infant motor development. Early Hum. Dev. 84, 479-485. doi: 10.1016/j.earlhumdev.2007.12. 009

Siddappa, A. M., Georgieff, M. K., Wewerka, S., Worwa, C., Nelson, C. A., and Deregnier, R.-A. (2004), Iron deficiency alters auditory recognition memory in newborn infants of diabetic mothers. Pediatr. Res. 55, 1034-1041. doi: 10.1203/01. pdr.0000127021.38207.62

Siddappa, A. J. M., Rao, R. B., Wobken, J. D., Casperson, K., Leibold, E. A., Connor, J. R., et al. (2003). Iron deficiency alters iron regulatory protein and iron transport protein expression in the perinatal rat brain. Pediatr. Res. 53, 800-807. doi: 10. 1203/01.pdr.0000058922.67035.d5

Siddappa, A. J. M., Rao, R. B., Wobken, J. D., Leibold, E. A., Connor, J. R., and Georgieff, M. K. (2002). Developmental changes in the expression of iron regulatory proteins and iron transport proteins in the perinatal rat brain. J. Neurosci. Res. 68, 761-775. doi: 10.1002/jnr.10246

Soewondo, S., Husaini, M., and Pollitt, E. (1989). Effects of iron deficiency on attention and learning processes in preschool children: bandung, indonesia. Am. J. Clin. Nutr. 50, 667-674.

Spruston, N. (2008). Pyramidal neurons: dendritic structure and synaptic integration. Nat. Rev. Neurosci. 9, 206-221. doi: 10.1038/nrn2286

Tamura, T., Goldenberg, R. L., Hou, J., Johnston, K. E., Cliver, S. P., Ramey, S. L., et al. (2002). Cord serum ferritin concentrations and mental and psychomotor development of children at five years of age. Obstet. Gynecol. Surv. 57, 493-494. doi: 10. 1097/00006254-200208000-00008

Taylor, E. M., Crowe, A., and Morgan, E. H. (1991). Transferrin and iron uptake by the brain: effects of altered iron status. J. Neurochem. 57, 1584-1592. doi: 10.1111/j. 1471-4159.1991.tb06355.x

Tran, P. V., Carlson, E. S., Fretham, S. J., and Georgieff, M. K. (2008). Earlylife iron deficiency anemia alters neurotrophic factor expression and hippocampal neuron differentiation in male rats. J. Nutr. 138, 24952501. doi: 10.3945/jn.108.091553

van Gelder, W., Huijskes-Heins, M., Cleton-Soeteman, M., van Dijk, J., and van Eijk, H. (1998). Iron uptake in blood-brain barrier endothelial cells cultured in iron-depleted and iron-enriched media. J. Neurochem. 71, 1134-1140.

Walter, T., De Andraca, I., Chadud, P., and Perales, C. G. (1989). Iron deficiency anemia: adverse effects on infant psychomotor development. Pediatrics 84, 7-17.

Walter, T., Kovalskys, J., and Stekel, A. (1983). Effect of mild iron deficiency on infant mentaldevelopment scores. J. Pediatr. 102, 519-522. doi: 10.1016/s00223476(83)80177-2

Weinberg, J., Brett, L. P., Levine, S., and Dallman, P. R. (1981). Long-term effects of early iron deficiency on consummatory behavior in the rat. Pharmacol. Biochem. Behav. 14, 447-453. doi: 10.1016/00913057(81)90301-4

Weinberg, J., Levine, S., and Dallman, P. R. (1979). Long-term consequences of early iron deficiency in the rat. Pharmacol. Biochem. Behav. 11, 631-638. doi: 10.1016/00913057(79)90254-5

Willows, N. D., Morel, J., and GrayDonald, K. (2000). Prevalence of anemia among james bay cree infants of northern quebec. CMAJ $162,323-326$.

Yehuda, S., Rabinovitz, S., Carasso, R. L., and Mostofsky, D. I. (2010). "Brain iron deficiency and cognitive and behavioral functions," in Iron Deficiency and Overload: From Basic Biology to Clinical Medicine, eds S. Yehuda and D. I. Mostofsky (Towota, NJ: Humana Press), 195-206.

Yehuda, S., and Yehuda, M. (2006). "Long lasting effects of infancy iron deficiency_Preliminary results," in Oxidative Stress and Neuroprotection (Vienna: Springer), 197-200.

Yehuda, S., and Youdim, M. B. (1989). Brain iron: a lesson from animal 
models. Am. J. Clin. Nutr. 50, 618-629.

Yehuda, S., Youdim, M. E., and Mostofsky, D. I. (1986). Brain iron-deficiency causes reduced learning capacity in rats. Pharmacol. Biochem. Behav. 25, 141-144. doi: 10.1016/0091-3057(86)90244-3

Young, M. F., Griffin, I., Pressman, E., Mcintyre, A. W., Cooper, E., Mcnanley, T., et al. (2012). Maternal hepcidin is associated with placental transfer of iron derived from dietary heme and nonheme sources. J. Nutr. 142, 33-39. doi: 10.3945/jn.111. 145961

Yu, G., Steinkirchner, T., Rao, G. A., and Larkin, E. (1986). Effect of prenatal iron deficiency on myelination in rat pups. Am. J. Pathol. 125, 620-624.

Conflict of Interest Statement: The authors declare that the research was conducted in the absence of any commercial or financial relationships that could be con- strued as a potential conflict of interest.

Received: 15 May 2013; accepted: 30 August 2013; published online: 23 September 2013.

Citation: Radlowski EC and Johnson $R W$ (2013) Perinatal iron deficiency and neurocognitive development. Front. Hum. Neurosci. 7:585. doi: 10.3389/ fnhum.2013.00585

This article was submitted to the journal Frontiers in Human Neuroscience.
Copyright (๑) 2013 Radlowski and Johnson. This is an open-access article distributed under the terms of the Creative Commons Attribution License (CC BY). The use, distribution or reproduction in other forums is permitted, provided the original author(s) or licensor are credited and that the original publication in this journal is cited, in accordance with accepted academic practice. No use, distribution or reproduction is permitted which does not comply with these terms. 